\title{
Relapses of desquamative glossitis in patients with gastroesophageal reflux disease
}

\author{
Nataliya Emelyanova*(i)

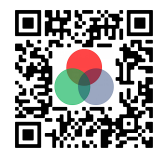 \\ Use your smartphone to scan this \\ QR code and download this article
}

\begin{abstract}
This article addresses the issues of pathological manifestations on the tongue of patients with gastroesophageal reflux disease (GERD), as well as the duration of the remission period after treatment. It was revealed that the patients with GERD who received treatment for desquamativeglossitis noted a significant decrease in the intensity of subjective and objective manifestations immediately after treatment. However, in cases where no repeated courses of treatment were undertaken, an unstable remission was observed in the oral cavity and new desquamation foci appeared on the tongue. As an example, the article describes the clinical case of a patient with GERD manifestations in the oral cavity who received treatment for desquamative glossitis in 2011.
\end{abstract}

Key words: gastroesophageal reflux disease, desquamative glossitis, remission, oral cavity

\section{INTRODUCTION}

Studying the combined pathology of the internal organs and the oral cavity plays an important role in modern practical medicine and requires the collaboration of dentists and internists ${ }^{1}$. Clinical manifestations in the oral cavity can precede many systemic pathologies and, when carefully studied, can help to identify signs and symptoms of various metabolic disorders, autoimmune processes, and diseases of internal organs. Thus, it is the oral cavity that becomes an important diagnostic area. Today, there is no doubt that the oral cavity has a close anatomical and pathogenetic relationship with many organs, with the mucous membrane of the oral cavity (oral mucosa) being an important integral component of the system of anatomical and physiological connections between the gastrointestinal tract organs.

In recent decades, acid-related diseases, of which gastroesophageal reflux disease (GERD) is a classic example, have occupied a significant place in the pathology of internal organs ${ }^{2}$. It stands to reason that GERD is called the "third millennium problem" due to its high prevalence in the world and significant worsening of the quality of patients' life. GERD is caused by impaired motor-evacuation function and is characterized by spontaneous, regularly repeated reflux of gastric or duodenal contents into the esophagus with development of characteristic clinical symptoms (heartburn, regurgitation, belching, etc.) ${ }^{3}$. The high prevalence rate of GERD is promoted by general risk factors, such as obesity, smoking, prolonged stress, use of certain medications, pregnancy and other factors ${ }^{4}$. However, the main causative factor is the antireflux barrier insufficiency which is initiated by the esophageal constrictor tonus.

Apart from the esophageal manifestations, GERD is represented by extra-esophageal "masks" which include cardiological, pulmonological, otorhinolaryngological and dental manifestations ${ }^{5,6}$. According to various studies, the main clinical dental manifestations are lesions of soft tissues in the oral cavity (e.g. burning and dryness in the oral cavity, oral mucosal aphthous, exfoliative cheilitis, tongue desquamation, and periodontal tissue disease), and changes in hard tooth tissues (carious and non-carious lesions) directly related to the nature of the refluxate and duration of its exposure ${ }^{7,8}$. Besides, according to the literature, it is known that GERD changes the qualitative and quantitative composition of non-stimulated saliva, which is a part of the pre-epithelial defense system of the anti-reflux barrier and plays a protective role against the action of hydrochloric acid on the oral cavity tissues ${ }^{9}$.

Treatment of GERD esophageal manifestations is carried out according to generally accepted standards and is aimed at reducing the damaging effect of refluxate, as well as at protecting esophageal mucosa. In patients with extra-esophageal manifestations, local methods of treatment are additionally applied, which are aimed at eliminating GERD manifestations in the oral cavity and affecting the main components of pathogenesis. terms of the Creative Commons

Attribution 4.0 International license.

The Open Access Publisher
Cite this article : Emelyanova N. Relapses of desquamative glossitis in patients with gastroe-sophageal reflux disease. Biomed. Res. Ther.; 7(10):4041-4044. 
Studying the duration of remission in the oral cavity in patients with GERD after treatment of dental manifestations, in particular benign migratory glossitis, is of particular interest.

Thus, the aim of the study was to investigate the recurrence of pathological manifestations in the tongue of patients with GERD after previous treatment.

\section{MATERIALS - METHODS}

Patients who received treatment of dental manifestations of GERD in 2010 - 2011 were invited to participate in the study. Consent was given by 38 patients who currently had esophageal signs of GERD; they were periodically followed up by a gastroenterologist. During previous treatment of extra-esophageal manifestations of GERD, these patients, in addition to standard anti-reflux therapy, were additionally recommended to take cytoprotector $(100 \mathrm{mg}, 3$ times a day for 30 days), and to receive symptomatic treatment of exfoliative cheilitis and desquamative glossitis (fermentation solutions and keratoplasty). Also, for all patients, an oral hygiene algorithm was developed according to an individual scheme. Statistical estimation was carried out using statistical programs and presented in the form of $\mathrm{M} \pm \mathrm{m}, \mathrm{t}$, Student criterion. Statistical analysis of data was carried out at a given reliability (0.95); the results were considered reliable provided that the significance level was $\mathrm{p}<0.05$.

\section{RESULTS - DISCUSSION}

As can be seen from Table 1, after previous treatment, there was stable remission, significant reduction in complaints, and clinical examination of the tongue in all patients. However, at the last visit, patients were worried about the burning tongue (a sense of scalding of the lateral surfaces and the tip), the swollen tongue (mainly in the morning), the plaqued tongue, change in taste sensitivity, bad breath, and unusual appearance of the tongue (bright spots on the tongue that migrated and sometimes occurred in new places).

Thus, patients noted brief remissions in the oral cavity that periodically occurred, during which dryness, burning, pain in the tongue (especially from spicy or hot foods), unpleasant aftertaste, and distortion of taste would completely disappear. Patients noted that the tongue increased in size during the period of GERD reoccurrence and got almost completely normalized during the period of remission. Objectively, during examination, the edematous tongue with a scalloped edge and tooth imprints on the lateral surfaces was observed (in $87.0 \%$ of the patients). The data obtained during previous examinations $(2010$ - 2011) are presented in Figure 1.

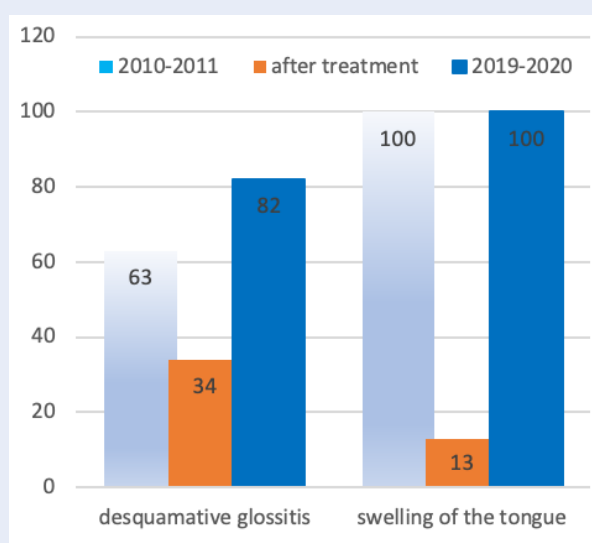

Figure 1: Tongue's condition in clinical observation dynamics. There is progressive deterioration to baseline in the absence of regular treatment.

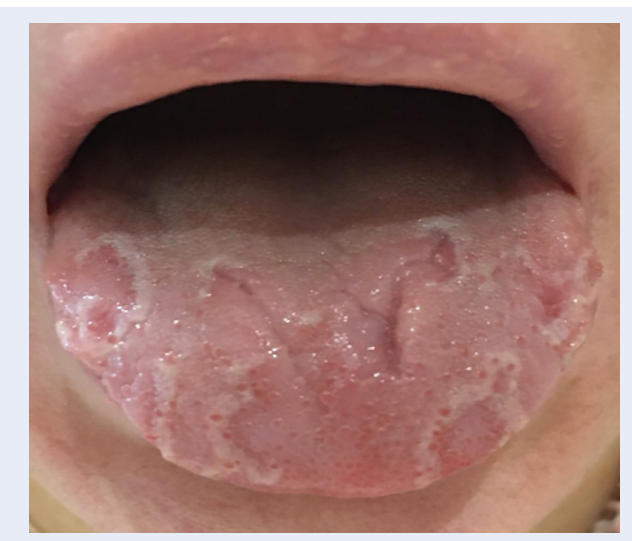

Figure 2: State of the tongue during the initial examination (2011). Combination of plaque, filiform papillae hypertrophy, pronounced folds and desquamation foci is observed.

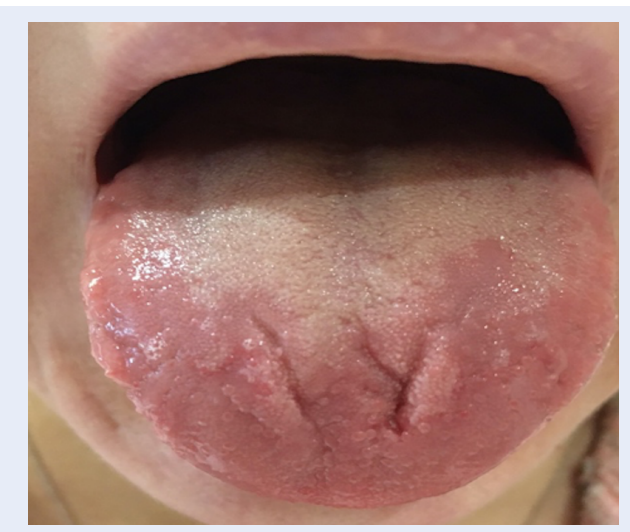

Figure 3: State of the tongue after treatment (2011). Epithelialization of foci, tongue papillae normalization, residual plaque are observed. 


\begin{tabular}{|c|c|c|c|}
\hline Complaints & $\begin{array}{l}\text { Before treatment } \\
(2010-2011)\end{array}$ & $\begin{array}{c}\text { After treatment }(2010 \\
-2011)\end{array}$ & $\begin{array}{l}\text { Last visit } \\
(2019-2020)\end{array}$ \\
\hline Dry mouth & $30(78.9 \pm 6.6)$ & $4(10.5 \pm 4.9)$ & $36(94.7 \pm 3.6)$ \\
\hline Sour and bitter taste in the oral cavity & $28(73.7 \pm 7.1)$ & $12(31.6 \pm 7.5)$ & $29(76.3 \pm 6.9)$ \\
\hline Burning and numbness of the tongue & $31(81.6 \pm 6.3)$ & $7(18.4 \pm 6.3)$ & $29(76.3 \pm 6.9)$ \\
\hline Dysgeusia & $28(73.7 \pm 7.1)$ & $12(31.6 \pm 7.5)$ & $12(31.6 \pm 7.5)$ \\
\hline Halitosis & $19(50.0 \pm 8.1)$ & $10(26.3 \pm 7.1)$ & $36(94.7 \pm 3.6)$ \\
\hline Plaqued tongue & $16(42.1 \pm 8.0)$ & $4(10.5 \pm 4.9)$ & $25(65.8 \pm 7.7)$ \\
\hline
\end{tabular}

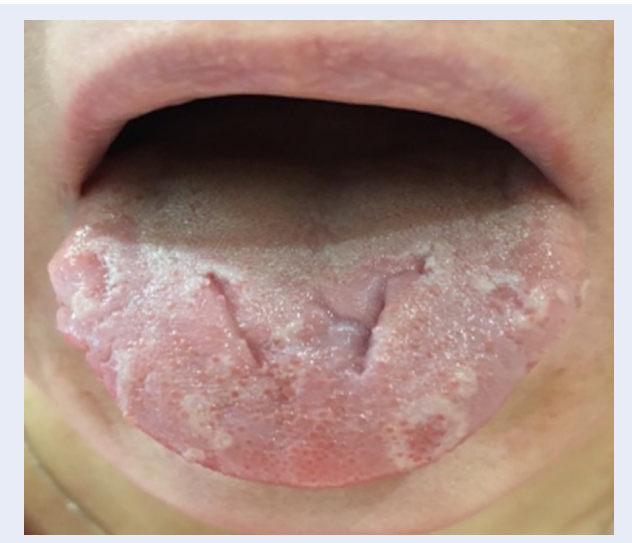

Figure 4: State of the tongue in 2020. Yellowish plaque, multiple foci of desquamation, filiform papillae hypertrophy, pronounced folds along the midline are observed.

On the back and lateral surfaces of the tongue, we observed areas of filiform papillae atrophy of different sizes, quantities and shapes, which were surrounded by whitish foci of keratosis. In 12 patients, benign migratory glossitis of the surface-migratory form was diagnosed, while 21 patients suffered from a fixed form of desquamation. Attention was also drawn to the plaque-covered root and the back of the tongue with a plaque index of $\mathrm{WTC}=4.8$; however, after treatment in $2010-2011$, this index was equal to an average of 1.7 in the group.

A clinical example is given as confirmation. Patient $\mathrm{K}$. attended a medical appointment to participate in the study. The diagnosis by a gastroenterologist was GERD. An endoscopic examination was carried out (for gastroesophageal reflux disease, $1^{\text {st }}$ degree, erythematous gastropathy). The patient had been sick for 10 years and had received the therapy prescribed by the gastroenterologist on demand. Past medical history showed that the patient never suffered from renal and hepatic insufficiency, connective tissue pathology, endocrine disorders, nor heart diseases. As well, they did not take any additional medications at the time of the study. The patient noted that after the dental treatment of benign migratory glossitis in 2011, persistent remission was maintained for a long time. However, over time, the patient began to feel the sense of discomfort in the tongue, and also spots of different diameters periodically appeared on its surface. Recently, she noted an almost constant increase in tongue size and its unusual appearance. Burning tongue was noted mainly at night and during meals. No salivation violations were noted.

The face is symmetrical; the skin and visible mucous membranes are without pronounced pathological changes. Nasolabial folds were moderately expressed and regional lymph nodes were not palpated. The mucous membrane of the oral cavity was pale pink, dry and swollen. The tongue was swollen, and there were tooth imprints on its lateral surfaces. The back of the tongue was covered with a small amount of white plaque which was removed by scraping, and the tongue filiform papillae were hypertrophied. Deep grooves along the midline were observed on the back of the tongue. Below is a photo of the patient at the last visit.

\section{CONCLUSION}

Patients with GERD have noticeable deviations from the norm; they have both subjective and objective indicators which are associated with exposure to highrising refluxate that often reaches the oral cavity. Typical dental complaints are constant as are periodic burning of the tongue, sour or bitter taste in the oral cavity, bad breath, distortion of taste, and plaque on the tongue. The clinical picture of changes in the tongue reflects subjective feelings and is manifested by pronounced tongue swelling, desquamations of various types and sizes, increased keratinization of the filiform papillae, and tongue plaque of whitish-yellow 
color. Identified changes are susceptible to correction by medications but require a regular approach due to short-term and unstable remission.

Early diagnosis and dental observation of patients with both initially diagnosed GERD and those previously treated will make it possible to prevent occurrence of pathological changes in the oral cavity, and to carry out timely and adequate treatment.

\section{ABBREVIATIONS}

None.

\section{ACKNOWLEDGMENTS}

I would like to thank all the colleagues who participated in the study.

\section{AUTHOR'S CONTRIBUTIONS}

Not applicable.

\section{FUNDING}

Not applicable.

\section{AVAILABILITY OF DATA AND MATERIALS}

The basic clinical data used to support the findings of this study are included within the article. The data used to support the findings of this study are restricted in order to protect patient's privacy, but available from the corresponding author upon request. (To contact Dr. N. Emelyanova natadenta@gmail.com)

\section{ETHICS APPROVAL AND CONSENT TO PARTICIPATE}

This study was conducted in accordance with the amended Declaration of Helsinki. The institutional review board approved the study, and all participants provided written informed consent.

\section{CONSENT FOR PUBLICATION}

The author hereby consents that the publisher publishes the work.

\section{COMPETING INTERESTS}

The authors declare that they have no competing interests.

\section{REFERENCES}

1. Yu YH, Chasman DI, Buring JE, et al. Cardiovascular risks associated with incident and prevalent periodontal disease. J Clin Periodontol. 2015;42(1):21-28. PMID: 25385537. Available from: https://doi.org/10.1111/jcpe.12335.

2. Miwa $H$, Igarashi $A$, Teng $L$, et al. Systematic review with network meta-analysis: indirect comparison of the efficacy of vonoprazan and proton-pump inhibitors for maintenance treatment of gastroesophageal reflux disease. Journal of Gastroenterology. 2019;54(8):718-729. PMID: 30919071. Available from: https://doi.org/10.1007/s00535-019-01572-y.

3. Bredenoord AJ, Weusten BL, Curvers WL, et al. Determinants of perception of heartburn and regurgitation. Gut. 2006;55:313318. PMID: 16120760. Available from: https://doi.org/10.1136/ gut.2005.074690.

4. Alshehri SS, Alzahrani MAM, Jan OM. Prevalence, Causes, Risk Factors and Updates of Management of GERD. EC Microbiology. 2020;16(2):01-08.

5. Romano C, Cardile S. Gastroesophageal reflux disease and oral manifestations. Ital J Pediatr. 2014;40:A73. Available from: https://doi.org/10.1186/1824-7288-40-S1-A73.

6. Sarath KKS, Mungara J, Venumbaka NR, et al. Oral manifestations of gastroesophageal reflux disease in children: A preliminary observational study. J Indian Soc Pedod Prev Dent. 2018;36:125-129. PMID: 29970628.

7. Pauwels A. Dental erosions and other extra-oesophageal symptoms of gastro-oesophageal reflux disease: Evidence, treatment response and areas of uncertainty. United European Gastroenterol J. 2015;3:166-170. PMID: 25922676. Available from: https://doi.org/10.1177/2050640615575972.

8. Watanabe M, Nakatani E, Yoshikawa H, et al Oral soft tissue disorders are associated with gastroesophageal reflux disease: retrospective study. BMC Gastroenterol. 2017;17:92. PMID: 28784097. Available from: https://doi.org/10.1186/s12876-0170650-5.

9. Milani DC, Venturini APC, Callegari-Jacques SM, et al. Gastrooesophageal reflux disease and dental erosions in adults. Eur J GastroenterolHepatol. 2016;28:797801. PMID: 26982339. Available from: https://doi.org/10.1097/MEG.0000000000000622. 